\title{
Inhibitive Effect of Costus afer Extracts on Mild Steel Corrosion in Acidic Medium
}

\author{
NNANNA Lebe A. ${ }^{1, a}$, JOHN Wisdom O. ${ }^{2, b *}$, ESIHE Tochukwu E. ${ }^{3, c}$ \\ DENKORO Kelechi C. ${ }^{4, d}$, OKPARAKU Victor I. ${ }^{5, e}$, UCHENDU Kings O. ${ }^{6, f}$ \\ ${ }^{1}$ Department of Physics, Michael Okpara University of Agriculture, Umudike. \\ 2,4,5,6 Department of Physics Electronics, Abia State Polytechnic, Aba. \\ ${ }^{3}$ Department of Chemistry, Abia State Polytechnic, Aba. \\ alebennanna@yahoo.com, bjwisdomoji@yahoo.com, 'esihetochi@yahoo.com, \\ dapogee5real@yahoo.com, eokparakuvictorik@gmail.com, ${ }^{f}$ kingsuchendu@gmail.com
}

Keywords: Costus afer, corrosion inhibition, Adsorption isotherm, physiosorption

\begin{abstract}
Inhibition effect of Costus afer on mild steel in $0.5 \mathrm{M} \mathrm{HCl}$ was studied using gravimetric method at room temperature. It was found out that Costus afer inhibited the corrosion of mild steel in the acidic environment and that the efficiency of inhibition increased as the concentration of the inhibitor in the environment increased. The data was used to test different isotherms and it suited the Langmuir isotherm. A value of $-15.995 \mathrm{kJmol}^{-1}$ was gotten for the $\Delta \mathrm{G}^{\mathrm{o}}$ ads. This value showed that the extracts of Costus afer inhibited the corrosion process through physiosorption mechanism. The high value of inhibition efficiency of the extract as the concentration increased in rationalized in terms of the increase in herteroatoms, saponnins and tannins which are present in the extract.
\end{abstract}

\section{Introduction}

Metals, especially mild steel has found extensive use in the industry and as such, exposed to degradation. Degradation of materials is not just a major problem but it has raised the level of risk involved in working with materials. There is need to reduce, to the barest minimum, the degradation of this metals not just for the risk factor involved but for the metal to last longer in service. When inhibitors are added to the corrosive environment, it slows down the rate of corrosion; other forms of inhibitors are used to coat the surface of the metal. Most corrosion inhibitors have been synthesized from cheap raw materials or chosen from compounds containing heteroatoms in their aromatic or long carbon chain $[1,2,3]$. These long chains may pose environmental hazards or threats.

The introduction of natural inhibitors known as green inhibitors, tend to solve this problem. Green corrosion inhibitors are biodegradable and do not contain heavy metals or other toxic compounds. There have been successful researches on inhibition of corrosion on metals in acidic and alkaline media with organic inhibitors by researchers like Nnanna [4, 5, 6, 7], Oguzie [8, 9, 10], Makanjuola [11], and Ugi [12, 13]. Costus afer, commonly called bush sugar cane or Monkey sugar cane [14, $15]$ is one of the organic inhibitors to be studied due to its medical importance. Several studies on the different parts of Costus afer reveal that the presence of essential oils, saponnin [16], mineral elements [17] and that it has found use as anti-inflammatory [18], antimicrobial [19], and therapeutic [18], amongst others. Corrosion inhibition potential of Costus afer on mild steel in $\mathrm{H}_{2} \mathrm{SO}_{4}$ medium has been reported. Also, reports on the inhibition of aluminum has been made, however, no reports on the corrosion inhibition of the leaf on mild steel in $\mathrm{HCl}$ has been made. This work presents the study of the inhibition of the corrosion of mild steel using Costus afer. 


\section{Materials and Method}

Mild steel sheet used for this study was gotten at Aba South Local Government of Abia State and were mechanically cut in to coupons of dimension $2 \mathrm{~cm} \times 2 \mathrm{~cm}$. The thickness of the mild steel was $1.32 \mathrm{~mm}$. Procedure for preparation of the mild steel is same as that used by Nnanna et al., 2015. The coupons were mechanically polished to remove coatings with Sic papers of different grades to obtain smooth surfaces that have no coatings on it. They were then degreased in ethanol, dried with acetone and stored in moisture free desiccators before being used for the studies. The percentage composition of the mild steel used (wt. \%) is: $\mathrm{C}=0.05, \mathrm{Mn}=1.13, \mathrm{Si}=0.05, \mathrm{P}=0.91, \mathrm{~S}=0.85$, $\mathrm{Cu}=0.09, \mathrm{~Pb}=0.15, \mathrm{Ve}=0.13, \mathrm{Mo}=0.08$ and $\mathrm{Fe}=96.56$.

\section{Sample collection and preparation}

Fresh samples of Costus afer (bush cane) were collected from a farm land in Abiriba, Ohafia Local Government Area of Abia State. The plant was identified, washed and air-dried. The air-dried plant specimen was pulverized. $10 \mathrm{~g}$ of the pulverized Costus afer was refluxed in $240 \mathrm{ml}$ of $0.5 \mathrm{M} \mathrm{HCl}$ solution $[5,7]$ and the resultant mixture was filtered to get a stock solution. From this stock solution, a concentration range of $0.1-0.4 \mathrm{~g} / \mathrm{L}$ was prepared using excess $0.5 \mathrm{M} \mathrm{HCl}$ as the solvent. These were prepared for the room temperature (303K).

\section{Gravimetric experiment}

All coupons prepared and stored were weighed in grams $(\mathrm{g})$ using an electronic weighing balance which had an accuracy of \pm 0.005 . These initial weights were recorded and the coupons were immersed into the corrosive environment. A blank experiment was conducted using purely $0.5 \mathrm{M}$ $\mathrm{HCl}$. At the end of each of the tests, the coupons were carefully brought out of the environment; nitric acid was used to quench further corrosion and then washed in ethanol. They were then dried in acetone and their new weights recorded. All tests were repeated in triplicates and values reported are the mean values of the experiment.

\section{Results and Discussion}

\section{Gravimetric studies, Corrosion Rates and Inhibition efficiency}

Values of weight loss, corrosion rates and inhibition efficiency (in percentage) were used to plot graphs against the concentration of the inhibitor (Costus afer) as shown in Figures $1-3$. The corrosion rate was determined from the equation below:

$$
C R=\frac{K \Delta w}{\rho A t}
$$

Where $C R$ - Corrosion rate in $\mathrm{mm} / \mathrm{yr} ; K$ - Corrosion rate constant (534 mpy; mils per year); $\Delta w$ Weight loss in grams; $\rho$ - Density of the steel $\left(\mathrm{g} / \mathrm{cm}^{3}\right) ; A$ - The exposed area of the coupon $\left(\mathrm{cm}^{2}\right) ; t$ Immersion time (hrs).

Close inspection of the graph reveals that the corrosion rate of mild steel in $0.5 \mathrm{M} \mathrm{HCl}$ was reduced the corrosion rate of the metal in the environment from as high as $0.4572 \mathrm{~mm} / \mathrm{yr}$ to as low as 0.0543 $\mathrm{mm} / \mathrm{yr}$. It can also be observed that the inhibition is dependent on the concentration of the inhibitor in the corrosive environment as can be seen on the graph where an increase in the concentration caused a decrease in the corrosion rate. This observed inhibitive action of the Costus afer extract could be attributed to the adsorption of its components on the mild steel surface leading to the formation of a layer of adsorbed molecules with the potentiality of isolating the metal surface from the aggressive acid solution and hence resulting in corrosion rate lowering. This result is similar to results obtained from researchers like [16], [20], [21] and many others. 


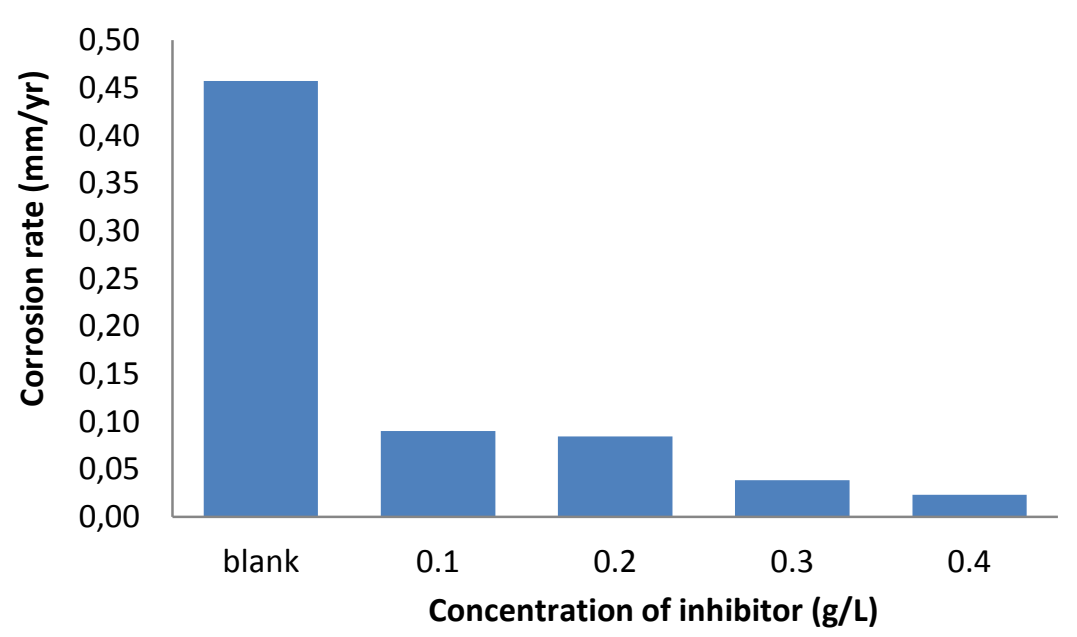

Figure 1: Variation of corrosion rate $(\mathrm{mm} / \mathrm{yr})$ with the concentration $(\mathrm{g} / \mathrm{L})$ of the inhibitor for mild steel in $0.5 \mathrm{M} \mathrm{HCl}$

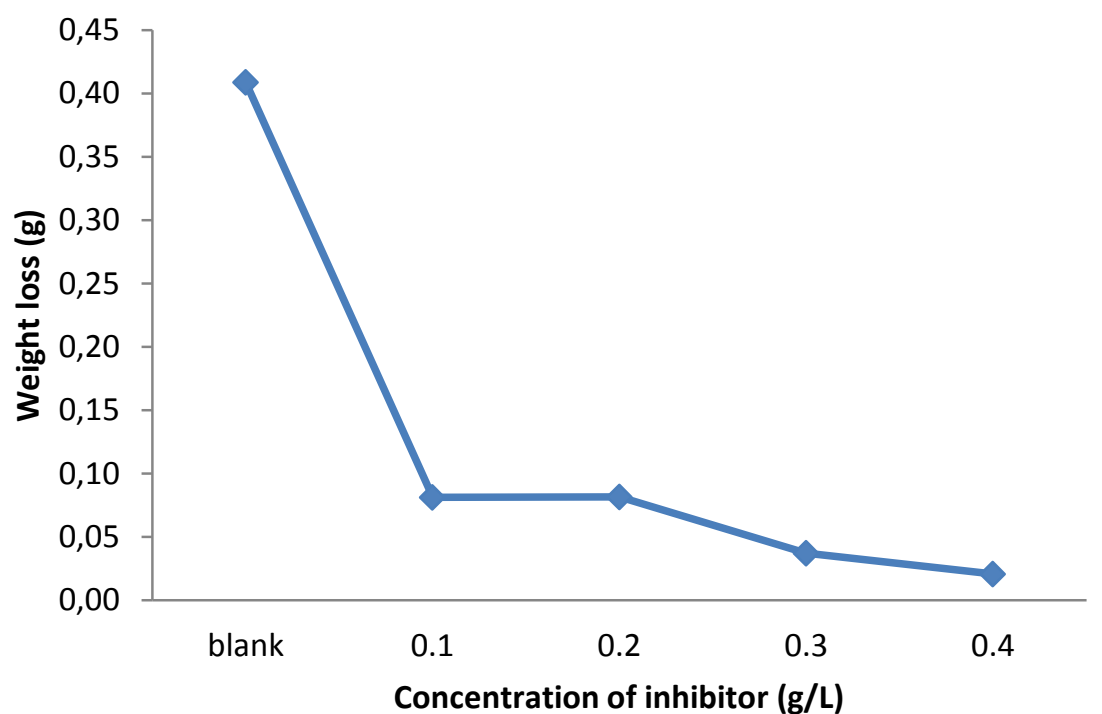

Figure 2: Variation of weight loss $(\mathrm{g})$ with the concentration $(\mathrm{g} / \mathrm{L})$ of the inhibitor for mild steel in $0.5 \mathrm{M} \mathrm{HCl}$

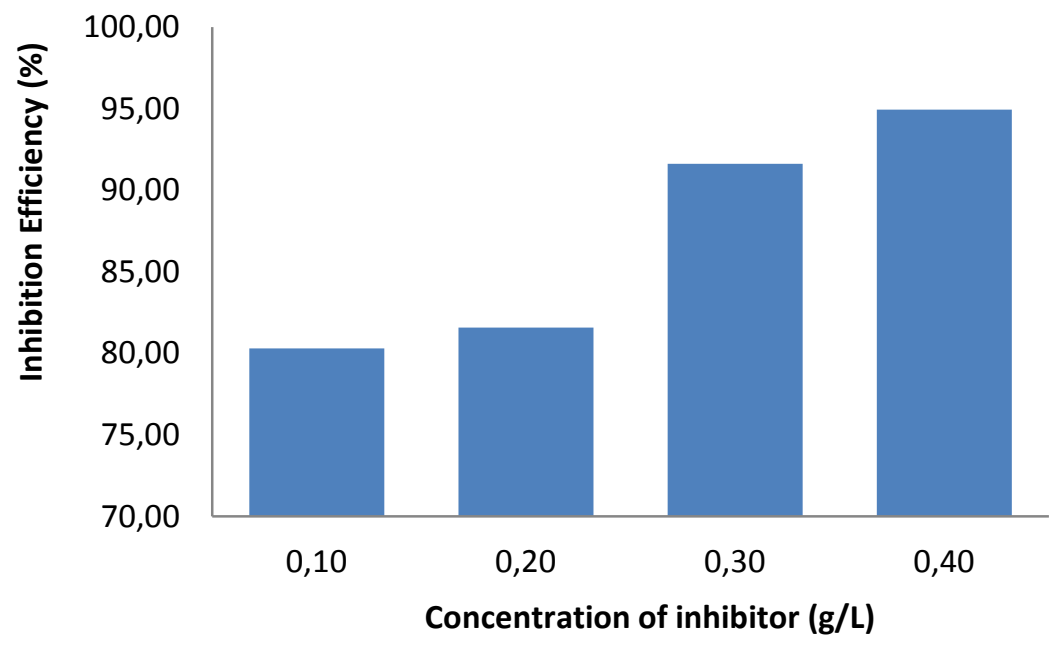

Figure 3: Variation of percentage inhibition efficiency with the concentration $(\mathrm{g} / \mathrm{L})$ of the inhibitor for mild steel in $0.5 \mathrm{M} \mathrm{HCl}$ 
The inhibition efficiency was calculated using the formula:

$$
I \%=\left(1-\frac{\rho_{\text {inh }}}{\rho_{\text {blank }}}\right) \times 100
$$

Where I\% represents the inhibition efficiency expressed in percentage, $\rho_{\text {inh }}$ is the corrosion rate in the presence of the inhibitor while $\rho_{\text {blank }}$ is the corrosion rate in the absence of inhibitor.

It was found as plotted in Figure 3, that the inhibition efficiency increased as the concentration increased getting as high as $91 \%$. Phytochemical screening of the leave extract had indicated the presence of flavonoids, tannins, alkaloids, phenols $[16,18,19]$. These phytochemical components may be responsible for the high inhibition efficiency Costus afer as these components when adsorbed to the surface of the metals become barriers to charge transfers between the environment and the metal. Assigning the inhibitive effect to a particular component is difficult at this stage because of the complex chemical composition of the extract although further investigation using surface analytical techniques will enable the characterization of the active materials in the adsorbed layer, thus assisting in identifying the most active ingredients in the adsorbed layer.

\section{Adsorption isotherms and mechanism of adsorption}

Various mechanisms have been proposed for inhibition of metal corrosion in several aggressive acidic media. Graphical tests were used to test the values of surface coverage $(\theta)$ in two different isotherms [23, 24] - the Langmuir and Temkin adsorption isotherms. The Langmuir adsorption isotherm is a model that explains adsorption by assuming that an adsorbate behaves as an ideal gas at isothermal conditions. At these conditions, the adsorbate's partial pressure is related to the volume of it adsorbed to the solid adsorbent. It is equivalent to the Hill equation [28]. The Temkin adsorption isotherm is a modification of the Langmuir adsorption isotherm. It takes into account indirect adsorbate-adsorbate interaction on adsorption isotherms. Experimentally, Temkin shows that the heat of adsorption would more often decrease than increase with increasing coverage [29].

The stability of adsorbed ions or molecules affects the inhibition of corrosion of mild steel in aggressive media like $0.5 \mathrm{M} \mathrm{HCl}$. Adsorption of components of Costus afer extract or its phytochemicals therefore is assumed to result in the formation of a surface complex that protects the surface of mild steel from the acid environment leading to inhibition of the corrosion process. In properly describing the mechanism of adsorption and nature of the surface complex formed, data obtained for degree of surface coverage $(\theta)$ were fitted into the adsorption isotherms - Langmuir and Temkin.

All these isotherms can be represented as follows $[4,10]$ :

$$
f(\theta, x) \exp (-\alpha \theta)=k C
$$

where $\mathrm{f}(\theta, \mathrm{x})$ is the configuration factor whose functional form depends on the physical model adopted and assumptions made in deriving the isotherm, $\theta$ is the degree of surface coverage, $x$ is known as the size ratio which gives the number of water molecule replaced by the inhibitor molecule, $\alpha$ is a molecular interaction parameter whose value depends on the type of molecular interactions in the adsorption layer and the degree of homogeneity of the surface, $\mathrm{C}$ is the inhibitor concentration while $k$ is the adsorption equilibrium constant which is temperature dependent according to the relation $[4,25,26]$. The correlation coefficients obtained $\left(\mathrm{r}^{2}=0.993\right)$ indicate that the adsorption of extracts of Costus afer onto the mild steel surface was best described by Langmuir adsorption isotherm (Figures $4-5$ ).

The plot of the ratio of concentration to surface coverage $(\mathrm{C} / \theta)$ against concentration $(\mathrm{g} / \mathrm{L})$ (Figure 4) and a plot of the surface coverage $(\theta)$ against the natural logarithm of the concentration $(\ln C)$ (Figure 5) displayed a straight line for the tested inhibitor in the media for both temperatures 
(Figure 4). The linear plot, with high correlation coefficient $\left(\mathrm{r}^{2}=0.993\right.$ for Langmuir isotherm) clearly reveals that the surface adsorption process of Costus afer on mild steel surface obeys the Langmuir adsorption isotherm. The plot supports the assertion that the mechanism of corrosion inhibition is due to the formation and maintenance of a protective film on the metal surface and that the additive cover both the anodic and cathodic sites through uniform adsorption following Langmuir isotherm.

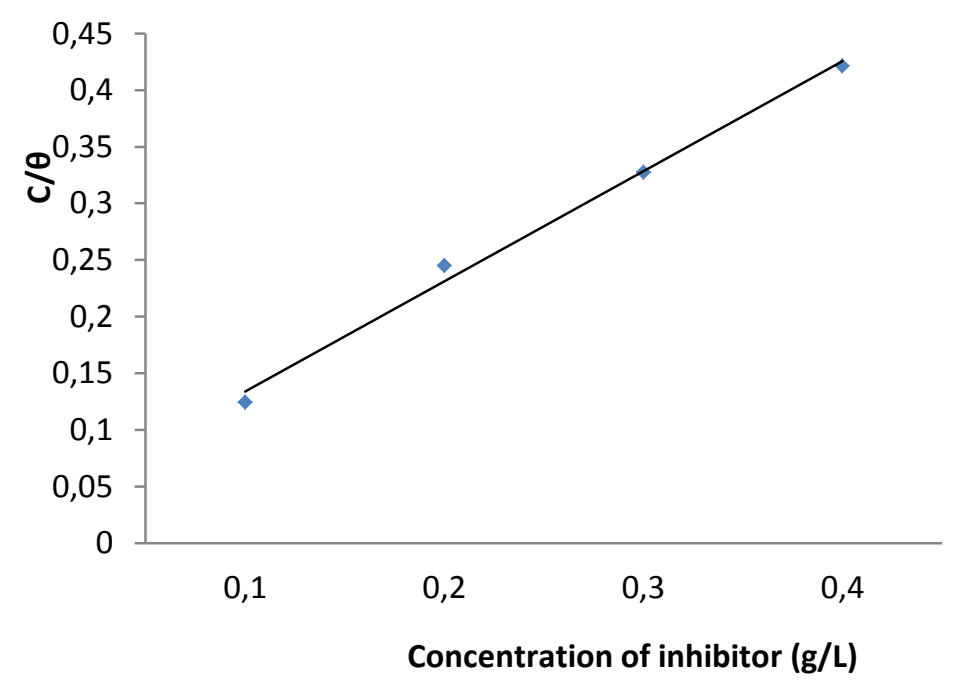

Figure 4: Langmuir adsorption isotherm for inhibition of mild steel in $0.5 \mathrm{M} \mathrm{KOH}$ by Costus afer extract.

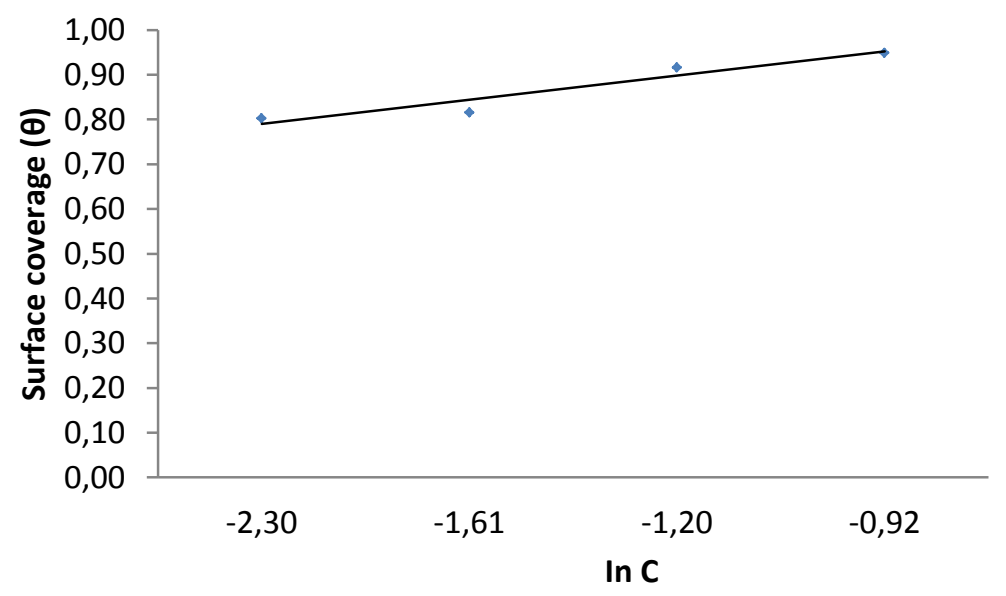

Figure 5: Temkin adsorption isotherm for inhibition of mild steel in $0.5 \mathrm{M} \mathrm{KOH}$ by Costus afer extract.

According to this model,

$$
C / \theta=1 /{ }_{k}+C
$$

where $\mathrm{C}$ is the inhibitor concentration while $k$ is the adsorption equilibrium constant which is temperature dependent according to the relation, $\theta$ is the degree of surface coverage. The free energy change of adsorption $\left(\Delta \mathrm{G}^{\mathrm{o}}\right.$ ads $)$ is directly related to $\mathrm{K}$ at a given temperature $(\mathrm{T})$ as shown in equation 5 and was used to calculate $\Delta \mathrm{G}^{\mathrm{o}}$ ads for Costus afer extracts:

$$
\Delta \mathrm{G}^{\circ}{ }_{\text {ads }}=-\mathrm{RT} \ln (55.5 \mathrm{k})
$$


Table 1: Values of Adsorption isotherms for corrosion inhibition of Costus afer on mild steel

\begin{tabular}{|c|r|r|r|r|r|}
\hline Adsorption isotherm & Temp (K) & Intercept & Slope & $\mathbf{R}^{\mathbf{2}}$ & $\Delta \mathbf{G}_{\text {ads }}^{\mathbf{0}}\left(\mathbf{k J m o l}^{\mathbf{1}}\right)$ \\
\hline Temkin & 303 & 0.054 & 0.736 & 0.917 & -17.470 \\
\hline Langmuir & 303 & 0.097 & 0.036 & 0.993 & -15.995 \\
\hline
\end{tabular}

A value of $-15.995 \mathrm{kJmol}^{-1}$ was gotten for $\Delta \mathrm{G}_{\text {ads. }}^{\mathrm{o}}$. A negative value obtained indicates that the adsorption was spontaneous. It has been established that values of $\Delta \mathrm{G}_{\text {ads }}^{0}$ of about $-20 \mathrm{~kJ} / \mathrm{mol}$ are characteristic of physical adsorption mechanism, while those more negative than $-40 \mathrm{~kJ} / \mathrm{mol}$ are consistent with chemical adsorption [4, 7, 27]. Physical adsorption (physisorption) is associated with intermolecular forces causing preferential binding of certain components of the extracts onto the adsorbent which is reversible on addition of heat while chemical adsorption involves chemical bond formation (coordinate covalent in nature) usually with release of large amount of heat.

\section{Conclusion}

Costus afer inhibited the corrosion of mild steel in $0.5 \mathrm{M} \mathrm{HCl}$ up to $94.95 \%$ at $0.4 \mathrm{~g} / \mathrm{L}$ in room temperature. The adsorption of the leaf to the metal, which caused the inhibition was tested to conform to the Langmuir isotherm and involved physiosorption. It is therefore recommended that Costus afer be used as an eco-friendly inhibitor to substitute the chemical inhibitors which are in use and may cause harm to the environment.

\section{References}

[1] O. K. Abiola, N. C. Oforka, E. E. Ebenso, A potential corrosion inhibition for acid corrosion of mild steel, Electrochemistry (2004), 20(9) $409-413$.

[2] R.B Rastoyi., M. M. Singh, K. Singh, M. Yadav, Organolic Dithiohydrazodicarbonamides as corrosion inhibitors for mild steel-dimethyl sulphoxide containing $\mathrm{HCl}$, Portugaliae Electrochimica Acta, (2005), 22, 315 - 332.

[3] A. O. James, N. C. Oforka, O. K. Abiola, Inhibition of corrosion of aluminium in hydrochloric acid by Pyridoxal hydrochloride, J. Corr. Sci. Eng. 7, Preprint (2005), 21, 1 - 10.

[4] L. A. Nnanna, B. N. Onwuagba, I. M. Mejeha, K. B. Okeoma, Inhibition effects of some plant extracts on the acid corrosion of aluminium alloy. Afr. J. Pure Appl. Chem., (2010), 4(1): 11-16

[5] A. N. Lebe, O. O. Israel, C. N. Onyinyechi, D. E. Nneka, J. O. Wisdom, Adsorption and Corrosion Inhibition of Gnetum africana Leaves Extract on Carbon Steel. International Journal of Materials and Chemistry (2013), 3(1): 10-16.

[6] L. A. Nnanna, W. O. John, O. Nwadiuko, Corrosion Inhibition Study of Aluminum AA3003 in Alkaline Medium by Palisota Hirsute Extract. International Journal of Engineering Research and Reviews, (2014), Vol. 2, Issue 4, pp: (113-118).

[7] L. A. Nnanna, W. O. John, E. C. Emenike, U. Ihekoronye, I. I. Dike, Corrosion Inhibition effect of Anthocleista djalonesis on mild steel in 1.0M HCl. IJERR (2015), Vol. 3, Issue 4, pp: (31-36).

[8] E. E. Ebenso, Effect of methyl red and halide ions on the corrosion inhibition of aluminium in $\mathrm{H}_{2} \mathrm{SO}_{4}$ : Part 2. Bull. Electrochemica (2004), 20: 551-559

[9] E. E. Ebenso, U. J. Ekpe, S. Umoren, J. Ekerete, O. K. Abiola, N. C. Oforka, S. Martinez, Corrosion inhibition studies of some plant extracts on aluminium in acidic medium. J. Corros. Sci. Techol., (2004), 1(1): 96-101 
[10] E. E. Ebenso, N. O. Eddy, A. O. Odiongenyi, Corrosion inhibition and adsorption properties of methacarbanol on mild steel in acidic medium. Portugaliae Electrochemica Acta., (2009), 27(1): $13-22$

[11] O. Makanjuola, C. Ebitei, A. Collins, K. O. Tambari, Corrosion Inhibition of Mild Steel in Hydrochloric Acid by Tannins from Rhizophora Racemosa. Materials Sciences and Applications, (2011), 2, 592-595.

[12] B. U Ugi. and F. E. Abeng, Corrosion Inhibition Effects and Adsorption Characteristics of Ethanol Extract of King Bitters Root (Andrographis paniculata) on Mild Steel in Hydrochloric and Tetraoxosulphate (VI) Acid Media. Fountain Journal of Natural and Applied Sciences (2013), 2(2): 10 - 21

[13] B. U. Ugi, I. E. Uwah, N. U. Ukpe, Inhibition and Adsorption impact of Leave Extracts of Cnidoscolus Aconitifolius on Corrosion of Aluminium Sheet in $1 \mathrm{M} \mathrm{HCl} \mathrm{Medium.} \mathrm{J.} \mathrm{Appl.}$ Sci. Environ. Manage. (2014), Vol 18(2): 319-325

[14] B. L. Nyananyo, Plants from the Niger Delta. Onyoma Research Publications, Port Harcourt (2006).

[15] G.E. Omokhua, Medicinal and Socio-Cultural Importance of Costus Afer (Ker Grawl) in Nigeria. International Multidisciplinary Journal, Ethiopia. (2011), Vol. 5 (5), Serial No. 22.

[16] B. I. Ekemini and E. U. Uwemedimo, Phytochemical profile, Adsorptive and Inhibitive behaviour of Costus afer extracts on aluminium corrosion in hydrochloric acid. Der Chemica Sinica, (2012), 3(6):1394-1405

[17] D. A Ukana, E. Uwemedimo and E. A. Aniekan, Evaluation of phytochemical, proximate and mineral element composition of stem of Costus afer (Bush cane). Asian Journal of Plant Science and Research, (2012), 2 (5):607-612.

[18] C. F. Ukpabi, K. N. Agbafor, O. K. Ndukwe, A. Agwu, S. N. Nwachukwu, Phytochemical Composition of Costus afer Extract and Its Alleviation of Carbon Tetrachloride - induced Hepatic Oxidative Stress and Toxicity. International Journal of Modern Botany (2012), 2(5): $120-126$.

[19] M. M. Akpan, C. S. Odeomena, , C. N. Nwachukwu, B. Danladi, Asian journal of plant science and research, (2012), (2): 335-341.

[20] I. M. Mejeha, A. A. Uroh, K. B. Okeoma, G. A. Alozie, The inhibitive effects of Solanum melongena L. Leaf extract on the corrosion of aluminium in tetraoxosulphate (VI) acid. Afr. J. Pure Appl. Chem., (2010) 4(8): 158-165

[21] E. E. Oguzie, Corrosion inhibitive effect and adsorption behaviour of Hibiscus sabdariffa on mild steel in acidic media. Portugaliae Electrochemica Acta., (2008), 26: 303-314

[22] A. Singh, V. K. Singh and M. A. Quraishi, Inhibition effect of environmentally benign Kuchla (Strychnos nuxvomica) seed extract on corrosion of mild steel in hydrochloric acid solution. Rasayan Journal of Chemistry (2010), 3(4) 811-824.

[23] A. Singh, A. Ishtiaque, V. K. Singh and M. A. Quraishi, Inhibition effect of environmentally benign Karanj (Pongamia pinnata) seed extract on corrosion of mild steel in hydrochloric acid solution". Journal of Solid State Electrochemistry (2011), 15(6): 1087 - 1097.

[24] A. Singh, E.E. Ebenso and M. A. Quraishi, Theoretical and Electrochemical Studies of Metformin as Corrosion Inhibitor for Mild Steel in Hydrochloric Acid Solution. International Journal of Electrochemical Science (2012), 7: 4766 - 4779.

[25] M. A. Ameer, E. Khamis, G. Al-Sanani, Adsorption studies of the effect of thiosemicarbazides on the corrosion of steel in phosphoric acid. Adsorpt. Sci. Tech., (2000), 18: $177-194$. 
[26] S. Martinez, Inhibitory mechanism of mimosa tannin using molecular modelling and substitutional adsorption isotherms. Mater. Chem. Phys., (2002), 77: 97-102

[27] M. Iannuzzi, G. S. Frankel, Mechanisms of corrosion inhibition of AA2024-T3 by vanadates. Corros. Sci., (2007), 49: 2371-2391

[28] D. A. H. Hanaor, M. Ghadiri, W. Chrzanowski, Y. Gan, Scalable Surface Area Characterization by Electrokinetic Analysis of Complex Anion Adsorption, Langmuir (2014), 30(50):15143 - 15152 .

[29] M. I. Temkin, V. Pyzhev, Acta Physicochima, USSR (1940), 12:327 